\title{
Mekanisme Fetch Dan Execute Pada Sistem Kinerja Control Processing Unit
}

\author{
M. Maulana Ikhsana ${ }^{1, *}$, Citra Mirna Watia ${ }^{2}$, Muhammad Yusuf Asharia ${ }^{3}$, Abd. Charis Fauzan ${ }^{4}$ \\ Pragam Studi Ilmu Komputer, Universitas Nahdlatul Ulama Blitar, Indonesia \\ ${ }^{1}$ ichsanmuhammad306@gmail.com; ${ }^{2}$ ctrmirna@gmail.com; ${ }^{3}$ yusufashari78@gmail.com; ${ }^{4}$ abdcharis@ @unublitar.ac.id \\ * corresponding author
}

ARTIKEL INFO

Article history

Diterima: 15 Juni 2019

Direvisi: 30 Juli 2019

Diterbitkan: 30 Agustus 2019

Keywords

Fetch dan Execute

CPU Komputer

Progam Eksekusi

Komponen CPU

\begin{abstract}
ABSTRAK
Tujuan pembuatan Jurnal ini adalah untuk mengetahui fungsi komponen-komponen CPU dan untuk mengetahui mekanisme CPU serta kinerja komputer saat melakukan proses instruksi. Dengan menggunakan metode fetch dan execute. Fungsi komputer di bentuk oleh eksekusi progam, progam yang di eksekusi berisi intruksi yang disimpan di memori, CPU melakukan tugas dengan cara mengeksekusi progam, sederhananya dengan mengolah intruksi yang terdiri dari 2 yaitu, intruksi fetch CPU, lalu CPU mengksekusi intruksi. Proses fetch dan eksekusi itulah cara untuk mengeksekusi progam, Untuk intruksi tunggal di perlukan pengolahan yang disebut siklus intruksi, dari riset yang dilakukan dan dari sumber-sumber yang telah di dapatkan memperoleh cara atau metode untuk melakukan eksekusi memory dan untuk melakukannya menggunakan tabel eksekusi program untuk mengatahuinya. Hasil dari metode yang di dapatkan itu sendiri adalah dari eksekusi progam yang terdapat pada komputer saat ini. CPU adalah komponen yang penting sebagai pengolah data berdasarkan intruksi di sistem komputer. Kesimpulannya fungsi CPU menjalankan progam yang disimpan dari dalam memori utama caranya adalah intruksi diambil, di uji dan dieksekusi satu persatu sesuai alurnya, sederhananya saja dari proses eksekusi progam dengan mengambil intruksi pengolah data yang terdiri dari dua langkah, yaitu operasi pembacaan instruksi (fetch) dan operasi pelaksanaan instruksi (execute).
\end{abstract}

\section{PENDAHULUAN}

Penelitian ini menjelaskan CPU atau prosessor dalam sebuah komponen yang berupa ic atau chip yang berbentuk persegi empat. chip ini merupakan suatu komponen utama pada sistem komputer sebagai suatu pengendali proses kinerja suatu komputer, serta dibantu dengan komponen lainnya. Pada dasarnya fungsi suatu cpu ialah menjalankan suatu progam di simpan dalam memori utama dengan mengambil suatu intruksi-intruksi, dan menguji intruksi tersebut serta mengeksekusinya satu persatu sesuai dengan alurnya. Perhitungan progam CPU bergerak dengan cara berurutan. Meski, dalam instruksinya di dalam CPU disebut juga instruksi lompatan, izin dari CPU dapat mengakses instruksi yang meletakkan bukan pada urutan itu, maka hal ini disebut instruksi yang bercabang (Branching Instruction) cabang instruksi tersebut terdapat cabang bersifat kondisional \& non kondisional. Suatu cabang yang sifatnya non kondisional berpindah ke instruksi yang terdapat di luaran alur dari instruksi itu. Cabang yang sifatnya kondisional menguji dulu hasil operasi sebelum melihat instruksi yang bercabang akan di eksekusi ataukah tidak di eksekusi. Pengujian sebuah data untuk cabang instruksi disimpan ke lokasi yang namanya flag. Penelitian ini sangat penting karena untuk memahami suatu progam yang disimpan dalam memori utama dengan mengambil fungsi CPU dan cara interaksinya dengan komponen lain. CPU sendiri ialah otak dari suatu komputer bisa disebut juga prosesor 
pusat, dan CPU tersebut adalah elemen yang paling penting dari sebuah sistem komputer. dapat ditinjau lebih jauh untuk proses eksekusi progamnya. Eksekusi progam mengambil pengolahan instruksi terdiri dua langkah, operasi instruksi pembacaan (fetch) dan operasi instruksi pelaksanaan (execute). Ada 3 konsep utama yaitu data dan instruksinya disimpan ke memori yang di baca sesuai tulisan tunggal, memori yang dialamati dengan cara melokasinya, tidang menggantungkan jenis data yang ada di dalamnya, eksekusi ini terjadi dengan sekuensial dari instruksi yang ada satu ke instruksi lainnya. CPU komputer digital dapat memprogamnya dan CPU (bersama dengan media penyimpanan utama fasikitas input atau output) merupakan suatu komponen penting dimasa perkembangan suatu komputer. suatu cpu yang dibangun sebagei satu komponen terintregasi dikenal dengan microprocessor [1].

\section{METODE}

Metode penelitian dilakukan dengan mengasumsikan bahwa PC memiliki Progam Counter; IR : Intruction Register; AC : Acumulator, Temporary Storage. Perintah terdiri dari 32bit, Alamat memori dengan daftar opcode dan informasi sebagei berikut [2] :

LOAD AC from memori ; ada dialamat 300

: 940 adalah 001000

LOAD to AC from memory; ada dialamat $301 \quad$ : 941 adalah 00001

STORE AC to memory; ada dialamat 302

: 942 adalah 00010

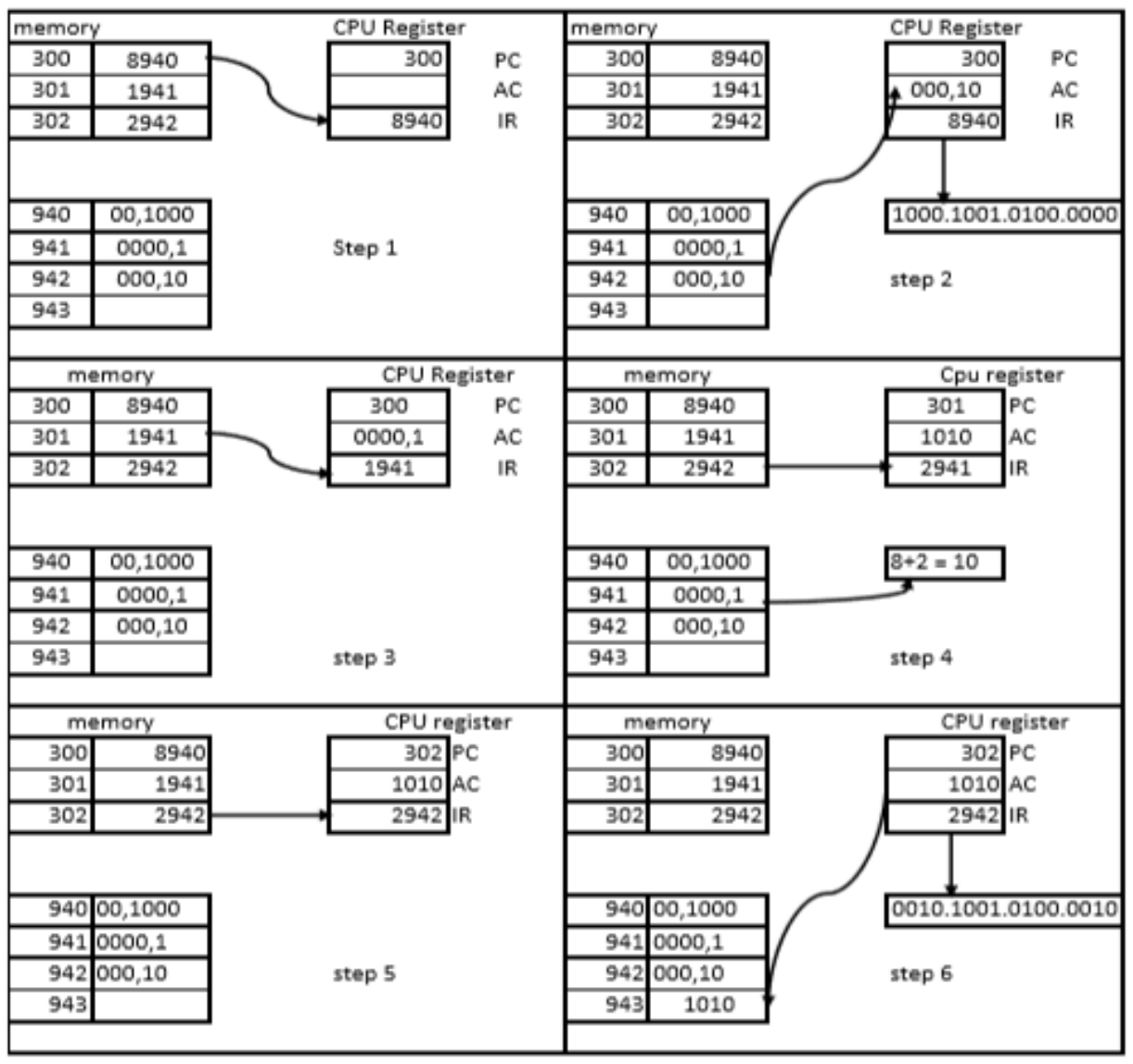

Gambar 1. Contoh Progam Eksekusi 
Gambar 1 adalah contoh progam eksekusi dari riset yang digunakan diketahui bahwa perintah 32 bit terbagi menjadi 4 bit up-code dan 12 bit alamat jika diasumsi bahwa progam (PC) bernilai yang berarti 300 ialah intruksi pertama, lalu intruksi yang berada pada lokasi 300 (alamat memori dari intruksi : 300) di loadkan ke (IR). Pertama, PC ke MAR, BACA. lalu ke dari MBR ke IR. 4 bit petama (Up-Code) dalam IR mengindikasikan bahwa AC di load. sementara 12 bit sisanya yaitu angka 940 itu menunjukkan alamat operan, nilai 8940 ialah bilangan desimal dimana angka 8 mewakili Up-Code dan 490 mewakili alamat memori, intruksi berikutnya (1941) dipanggil dari lokasi 301 pada progam counter meningkat semisal 1x. Kode 1941 memiliki maksud bahwa 1 artinya ADD, sedangkan 941 adalah alamat data di eksekusi yang mau dieksekusi intruksi. isi dari memori yang lama serta konten yang berlokasi di alamat 941 ditambahkan kemudian hasilnya akan disimpan di Akumulator, intruksi selanjutnya 1942 dipanggil dari lokasi 302 dan progam counter incremeent (meningkat) yang artinya simpan konten dari akumulator memori padda lokasi 942 [3].

\begin{tabular}{|l|c|c|c|}
\hline 001000 & 00001 & $\mathbf{0 0 0 1 0}$ & $\mathbf{0 0 0 0 0 0 0 1 0 1 0 1 1 1 1 0}$ \\
\hline Label & Opcode & Operand & Komentar \\
\hline
\end{tabular}

Gambar 2. Format Instruksi

Gambar 2 adalah format instruksi, label yang digunakan untuk nama yang menyediakan simbolik dari alamat memori. Label ini adalah sebuah pengarah yang digunakan dalam baris progam yang bercabang ke baris label. Untuk mengakses sebuah data perlu menggunakan nama yang berupa simbolik. Panjang maksimum label hingga 32 karakter, ada juga yang membatasi sampai 6 karakter. Kode Operasi (Opcode) isinya singkatan simbolik yang beroperasi sebuah kode yang akan dikerjakan. Operand untuk menetapkan konstanta, immediate data, label, sebuah alamat, dan register memori. Komentar menyediakan tempat dokumentasi untuk menjelaskan yang dikerjakan dengan cara debugging maupun untuk maintenance. Ini adalah Bahasa Rakitan (assembly) yang terdapat di sistem kinerja CPU [4].

\section{PEMBAHASAN}

Dari riset yang dilakukan dan dari sumber-sumber yang telah didapatkan, maka diperoleh cara atau metode untuk melakukan eksekusi memory dan untuk melakukannya menggunakan tabel eksekusi program untuk mengatahuinya. Hasil dari metode yang di dapatkan itu sendiri adalah dari eksekusi progam yang terdapat pada Komputer saat ini. CPU adalah komponen yang penting sebagai pengolah data dengan berdasarkan pada instruksi di sistem komputer. Dasarnya saja fungsi dari adalah CPU menjalankan progam yang dapat disimpan didalam memori utama caranya adalah intruksi diambil, di uji dan dieksekusi satu persatu sesuai alurnya, Ada beberapa komponen utama CPU [5] yaitu

- ALU (Arithmetic and Logic Unit )

- Control Unit

- Register

- CPU interkoneksi 


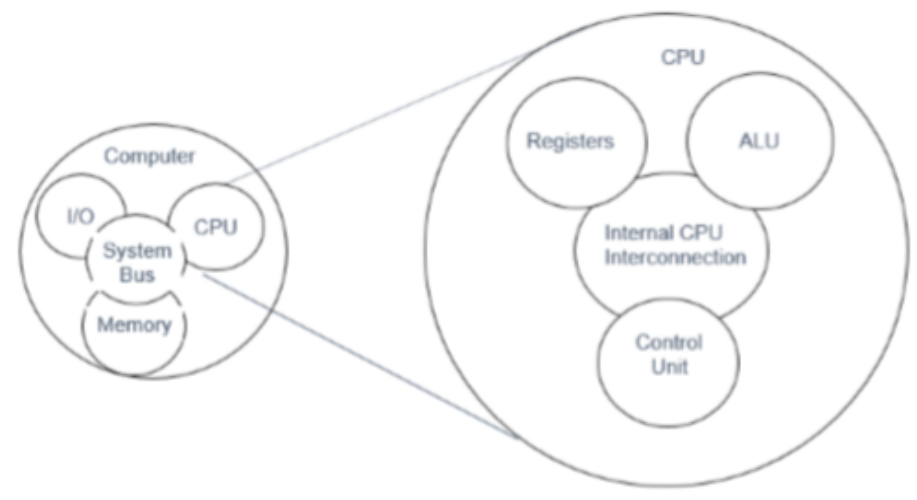

Gambar 3. Komponen CPU

Gambar 3 adalah komponen CPU, ALU merupakan unit komputer pengolah data dari aritmetika maupun dari logika. ALU aritmetika mempunyai 2 unit yaitu unit Logika Boolean dan Unit Aritmetika yang ada spesifikasinya sendiri. Control Unit fungsinya adalah mengontrol operasi CPU secara menyeluruh, sehingga terjadi sinkrronisasi kerja antara komponen di dalam fungsi operasi. Unit Control mengambil intruksi di memori utama meneentukannya jenis jenis intruksi. Register ialah media penyimpanan internal yang berupa CPU digunakan untuk proses pengolah data bersifat sementara, menyimpan data yang diolah maupun data, digunakan untuk pengolah yang lanjutan. Interkoneksi CPU, sistem yang mempunyai koneksi terhubung dengan bus bersama komponen eksternal maupun internal. Komponen internal CPU berupa ALU, register serta Unit Control, sedangkan eksternal berupa piranti masukan, memori utama, dan piranti I/O [6].

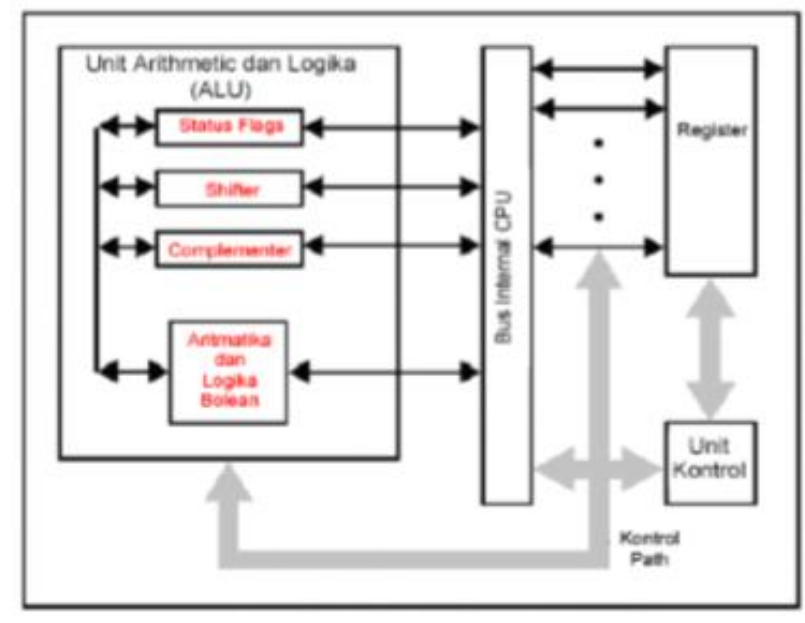

Gambar 4. Struktur internal CPU

Gambar 4 adalah Struktur internal CPU, Progam eksekusi berproses dengan cara mengambil instruksi pengolah data dari dua langkah itu adalah operasi pembaca instruksi (fetch) dan pelaksana instruksi (execute). Berikut Siklus fetch serangkaian proses yang terjadi di eksekusi progam.

1. Dengan siklus instruksi, CPU awalnya hanya membaca instruksi di memorinya saja.

2. Ada register didalam CPU fungsinya mengawasi serta menghitung instruksi yang ada di selanjutnya, disebut juga Program Counter (PC).

3. Di dalam PC menambah satu hitungan setiap kalinya maka CPU akan membaca instruksi itu.

4. Instruksi dibaca dengan masuknya di register instruksi (IR) [7]. 
5. Instruksinya membentuk bilangan binner yang bisa diinterpretasikan CPU kemudian dilakukanlah aksi yang ada penjelasan berikutnya [8].

Sederhananya saja dari proses eksekusi progam dengan mengambil intruksi pengolah data dua langkah tersebut, yaitu operasi pembaca instruksi (fetch) dan operasi pelaksana instruksi (execute) [9]. Aksi CPU ada 4 ialah:

1. CPU-Memori, data dipindah dari CPU ke memor

2. CPU-Input dan Output perpindahan data di CPU ke modul input atau output

3. pengolahan suatu data CPU dilakukan dengan cara operasi aritmatika seta dengan logika data

4. Kontrol, ialah instruksi pengontrolan fungsi contohnya saja instruksi perubahan urutan eksekusi [10].

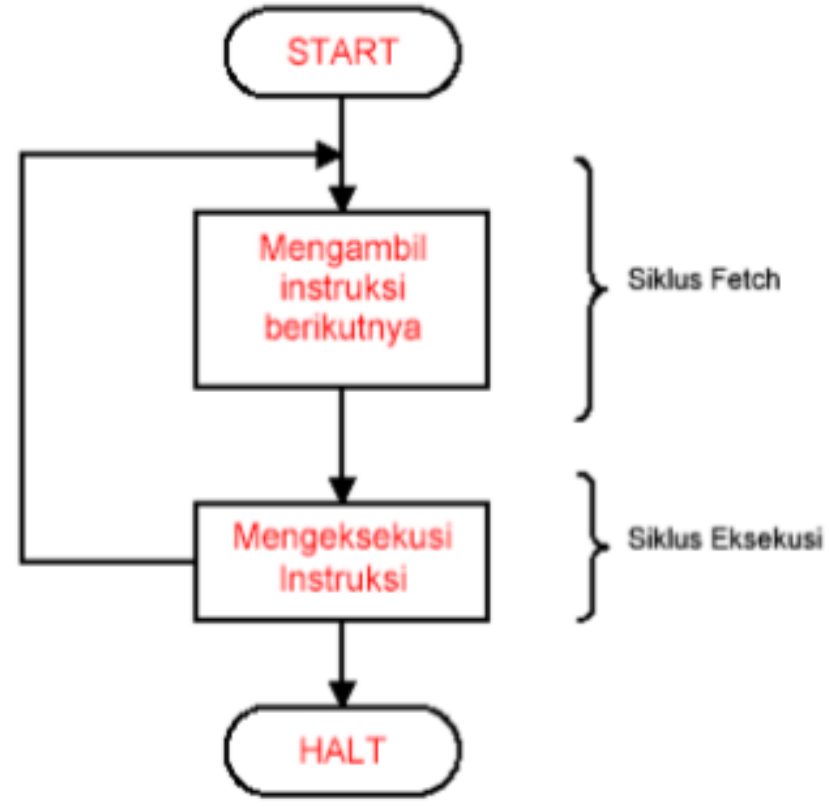

Gambar 5. Alur diagram siklus instruksi

Gambar 5 adalah Alur diagram siklus instruksi, Instruction Fetch (IF), merupakan pengambil atau membaca instruksi ke CPU dari lokasi memorinya. IOD/Instruction Operation Decoding adalah menganalisa intruksi yang bertujuan sebagai penentu jenis operasi yang kemudian akan dibuat dan operan yang mau dipakai. OAC/Operand Addres Calculation, adalah yang bertugas sebagai penentu alamat operand, keadaan ini harus dilaksanakan apabila proses memperlibatkan referensi operand yang terdapat dimemori. OF/Operand Fetch adalah keadaan dalam mengambil operand di modil I/O ataupun dari memorinya. Data Operand (DO). adalah operasi yang diperintahkan dalam instruksi. Operand Store (OS) ialah penyimpanan hasil eksekusi yang dilakukan di dalam memori.

\section{KESIMPULAN}

Berdasarkan penelitian yang telah diuraikan, maka dapat mengambil kesimpulan bahwa siklus yang telah terjadi didalam PC saling berhubungan dengan satu sama lain dan bertambah baiknya ke alamat instruksi berikutnya atau dapat diperbarui pada alamat yang berbeda dimana instruksi akan mengambil dari siklus tersebut lalu digunakan kembali, dengan menggunakan metode tertentu seperti yang digunakan yaitu metode eksekusi progam. 


\section{REFERENSI}

[1] Abdani, F., Robbi, A., Prasetijo, A. B., \& Widianto, E. D. (2019). Perbandingan Kinerja Block Storage Ceph dan ZFS di Lingkungan Virtual Performance Comparison of Ceph and ZFS Block Storage in Virtual Environment. 7(November 2018), https://doi.org/10.14710/jtsiskom.7.1.2019.7-11

[2] Ariawan, J., \& Irawan, O. D. M. (2014). Kajian Penggunaan Mikrotik Router Operating Sistem sebagai Router pada Jaringan Komputer pada PT. Bilna Jakarta. Jurnal Sisfotek Global, 4(1). Retrieved from https://stmikglobal.ac.id/journal/index.php/sisfotek/article/view/43

[3] Fitriyana. (2010). Jurnal Organisasi Dan Arsitektur Komputer, 1-66.

[4] Irma, J. (2012). Evolusi Komputer, Kinerja Komputer Dan Interconnection Networks Dalam Perkembangan Dunia Teknologi Informatika. Universitas Indrapasta PGRI Jakarta. Jurnal Arsitektur Komputer, 63-75.

[5] Nur Hayati, S.ST, M. (2017). ORGANISASI DAN ARSITEKTUR KOMPUTER, 1-67.

[6] Oktafiana, E., Informasi, J., Komputer, T., \& Centre, E. E. (1944). TUGAS JURNAL ILMIAH. (21), 15.

[7] Purwadi. (1978). Arsitektur Komputer tentang Mekanisme Kerja Prosesor dalam Menjalankan Intruksi dan Interupsi pada Sistem Kerja Komputer. Jurnal Ilmiah SAINTIKOM, 113-120.

[8] Samsumar, L. D., \& Gunawan, K. (2017). Analisis dan Evaluasi Tingkat Keamanan Jaringan Komputer Nirkabel (Wireless LAN); Studi Kasus di Kampus STMIK Mataram. Ilmiah Teknologi Informasi Terapan, 4(1), 73-82.

[9] Stallings, W. (2010). COMPUTER O RGANIZATION AND A RCHITECTURE DESIGNING FOR P ERFORMANCE, 8-15.

[10] Suharini, Y. S. R. I. (2014). Arsitektur Program Paralel Berbasis Message-Passing Interface. 7(1), 111. 